\title{
Heterotopic ossification following hip arthroplasty: a comparative radiographic study about its development with the use of three different kinds of implants
}

\author{
Carlo Biz ${ }^{1 *}$, Davide Pavan, Antonio Frizziero², Ala Baban² and Claudio lacobellis ${ }^{1}$
}

\begin{abstract}
Background: Our purpose was to record the incidence of heterotopic ossification (HO) following hip replacement by different variables to identify patient groups that are likely to develop $\mathrm{HO}$ in the absence of a prophylactic protocol.

Methods: Radiographically, we studied 651 patients having undergone hip joint replacement, evaluating three kinds of implants: ceramic-ceramic-coupled total hip replacement (THR), TriboFit with polycarbonate urethane-ceramic coupling and endoprosthesis. Each patient was analysed for $\mathrm{HO}$ development by age, gender, diagnosis, presence of previous ossifications, surgical approach and kind of implant. Within the population that developed HO, data were assessed for correlation with severity of ossification graded according to Brooker classification.

Results: The overall incidence of HOs was $59.91 \%$. The factors increasing their incidence in the univariate analysis were as follows: lower age of the patients with $\mathrm{HO}$ (mean 77.6 years, $p=0.0018$ ) than those subjects who did not develop HO (mean 80.2 years); male gender (64.4 \%, $p=0.1011)$; diagnosis of coxarthrosis $(72.7 \%, p=0.0001)$ compared to femur neck fracture (55.9\%, $p=0.0001)$; presence of previous $\mathrm{HO}(76.2 \%, p=0.0260)$; lateral approach (65.5\%) as opposed to anterior-lateral approach (55.6\%, $p=0.0163)$; and ceramic-ceramic THR (68.1\%) and TriboFit $(67.0 \%)$ compared to endoprosthesis $(51.3 \%, p=0.0001)$.

During multivariate analysis, the presence of $\mathrm{HO}$ after previous hip surgery $(p=0.0324)$ and the kind of implant ( $p=0.0004$ ) showed to be independent risk factors for the development of HO. Analysing the population that developed $\mathrm{HO}$, we found that the severity of ossification by Brooker classification was influenced by gender $(p=0.0478)$ and kind of implant $(p=0.0093)$.

Conclusions: In agreement with the literature, our radiographic study confirms the following risk factors of $\mathrm{HO}$ development in absence of any prophylactic treatment: male gender, diagnosis of coxarthrosis compared to femur neck fracture, previous $\mathrm{HO}$, surgical approach and kind of implant. In particular, Hardinge-Bauer and Watson-Jones surgical approaches, characterized by a wide exposure of the coxofemoral joint, and ceramic-ceramic THR and TriboFit implants significantly increase the development of $\mathrm{HO}$.
\end{abstract}

Keywords: Heterotopic ossification, Periarticular ossification, Hip arthroplasty, Hip endoprosthesis, Prophylactic therapy

\footnotetext{
* Correspondence: carlo.biz@unipd.it

'Orthopaedic and Traumatology Clinic, Department of Surgery, Oncology and Gastroenterology DisCOG, University of Padua, via Giustiniani 2, 35128 Padova, Italy

Full list of author information is available at the end of the article
}

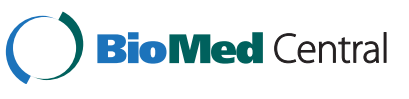

(C) 2015 Biz et al. Open Access This article is distributed under the terms of the Creative Commons Attribution 4.0 International License (http://creativecommons.org/licenses/by/4.0/), which permits unrestricted use, distribution, and reproduction in any medium, provided you give appropriate credit to the original author(s) and the source, provide a link to the Creative Commons license, and indicate if changes were made. The Creative Commons Public Domain Dedication waiver (http://creativecommons.org/publicdomain/zero/1.0/) applies to the data made available in this article, unless otherwise stated. 


\section{Background}

Heterotopic ossification $(\mathrm{HO})$ is the presence of the lamellar bone within soft tissues where the bone physiologically does not exist. One of the most common forms of $\mathrm{HO}$ is that which intervenes in periarticular soft tissue after hip replacement, with a mean incidence of $53 \%$ reported in the literature [1]. Multiple studies have been performed to date, but aetiopathogenesis of $\mathrm{HO}$ is still uncertain. Several authors [2-11] have confirmed some risk factors including male gender, presence of prior $\mathrm{HO}$, previous hip surgery and lateral and anterolateral hip approaches. Some pathologies have been associated with a higher rate of $\mathrm{HO}$, such as ankylosing spondylitis, hypertrophic osteoarthritis, diffuse idiopathic skeletal hyperostosis, Paget disease, Parkinson's disease and rheumatoid arthritis. The incidence of HO in hip surgery can be vastly different in different ethnic groups. Some studies [2-4, 12] reported a higher incidence of $\mathrm{HO}$ in African-American patients following acetabular fracture surgery and in Japanese population because of spastic limb, traumatic brain injuries, spinal cord lesions, nerve injuries and neurological disorders, when compared with Europeans. The most widely used classification system for $\mathrm{HO}$ following hip arthroplasty was developed by Brooker et al. [13] in 1973. Effective measures (NSAIDs, radiation therapy and selective inhibitors of COX2) to prevent $\mathrm{HO}$ after prosthetic hip surgery are well documented [14-20]. However, there is no universal agreement as to which therapeutic protocol is the best.

The aim of this radiographic and retrospective study, performed on a wide cross-section of patients having undergone hip replacement, was to record the incidence of $\mathrm{HO}$ by the following variables: three different kinds of implants, surgical approach, pre-existing $\mathrm{HO}$, age, sex and diagnosis of diseased hip, as well as identify patient groups that are likely to develop $\mathrm{HO}$ in the absence of a prophylactic protocol.

\section{Materials and methods}

Collection and statistical analysis of data were performed at our Orthopaedic and Traumatology Clinic during a period of 24 months, from September 2012 to August 2014, by an external and independent investigator (PD) not involved in the patients' treatment. Information matter of the research was learnt consulting retrospective case histories, surgical procedures and radiographic reports from the computerized archives of our hospital. Radiographic data of $\mathrm{HO}$ were obtained reading the radiographic computerized images taken in the preoperative, postoperative and follow-up periods, available in the computer system of our institute. We used a diagnostic LCD CORONIS 3MP display (produced by Barco, Rome, Italy) as a viewing monitor to determine the presence and extent of $\mathrm{HO}$.
To classify HOs, we used Brooker classification that identifies four grades of $\mathrm{HO}$ based on an anteroposterior radiograph of the pelvis:

- Grade 1: the presence of isolated bone fragments of any size within periarticular soft tissue

- Grade 2: the presence of bone spurs from the pelvis or femur with at least $1 \mathrm{~cm}$ between opposing bone surfaces

- Grade 3: the presence of bone spurs reducing space between opposing bone surfaces to less than $1 \mathrm{~cm}$

- Grade 4: ossification with apparent ankylosis of the hip

In this study, we examined data from a total of 823 patients who underwent, from 2006 to 2013, a surgical hip replacement in our Orthopaedic Clinic with one of the following kinds of implant: ceramic-ceramic total hip replacement (THR), the TriboFit system with polycarbonate urethane-ceramic coupling and endoprosthesis. All subjects participating in this study received a thorough explanation of this study and gave their oral and written informed consent to publish the data. The study was performed in accordance with the ethical standards of the 1964 Declaration of Helsinki as revised in 2000.

Patients were included in the study on the basis of the presence in our computerized database of a minimum follow-up control at 6 months from the surgical intervention (mean follow-up time $32.66 \pm 13.17$ months; range 672 months). This period was considered the sufficient minimum to observe the development of $\mathrm{HO}$ after hip surgery. With this premise, data from a total of 651 patients were analysed. None of the patients studied was treated with prophylactic drugs against formation of periarticular $\mathrm{HO}$ or other preventive therapies.

The following information was obtained for each patient from our database:

- Preoperative: age, sex, diagnosis of diseased hip, pre-existing $\mathrm{HO}$ of the hip following prior surgery, previous hip surgery on the same side

- Operative: surgical approach to the hip, kind of implant

- Postoperative: presence or absence of periarticular $\mathrm{HO}$ in the surgical hip classified according to Brooker system as mild (grade 1), moderate (grade 2 ), severe (grade 3 ) and very severe (grade 4 )

The collected data were statistically assessed for correlation with the development of $\mathrm{HO}$, independently from their grade, using the chi-square test of independence with a $p$ value $<0.05$ as significance level. Then, factors found to significantly increase development of ectopic bone were compared individually using multivariate analysis (logistic 
regression) to rule out interdependence. Further, a possible relationship with statistical significance was analysed between each singular risk factor and the presence of $\mathrm{HO}$ considering its grade according to Brooker classification. Storage and statistical analysis of data were performed using SAS 9.2 (SAS Institute Inc., Cary, NC, USA) for Windows.

\section{Results}

The analysed cohort consisted of 440 women (67.59 \%) and 211 men $(32.41 \%)$ with a mean patient age of 78.7 years (range 19-98 years) at the time of surgery.
Diagnosis of diseased hip included traumatic femoral neck fracture in 517 patients (79.42\%), coxarthrosis in 99 patients $(15.21 \%)$ and other diagnoses in 35 patients (5.37 \%). The latter included 11 femoral head necrosis, 1 hip instability, 2 painful THRs, 6 hip surgical revisions for prosthesis mobilization, 3 surgeries after spacer positioning, 2 pathological fractures, 1 revision for intolerance to metal, 1 hip dysplasia, 2 acetabular fractures, 1 posttraumatic stiffness of the hip, 1 pseudoarthrosis after femoral neck surgery with percutaneous screws, 1 hip arthritis, 2 previous femoral neck surgeries with percutaneous screws and 1 pertrochanteric fracture with severe coxarthrosis

a

600

500

400

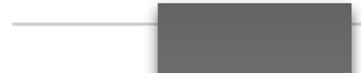

300

200

100
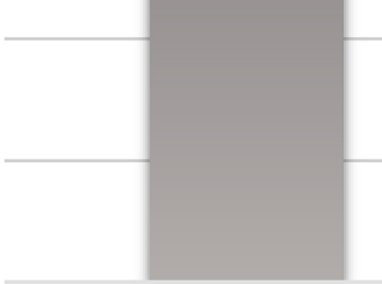

0

femoral neck fracture

coxarthrosis

others

b

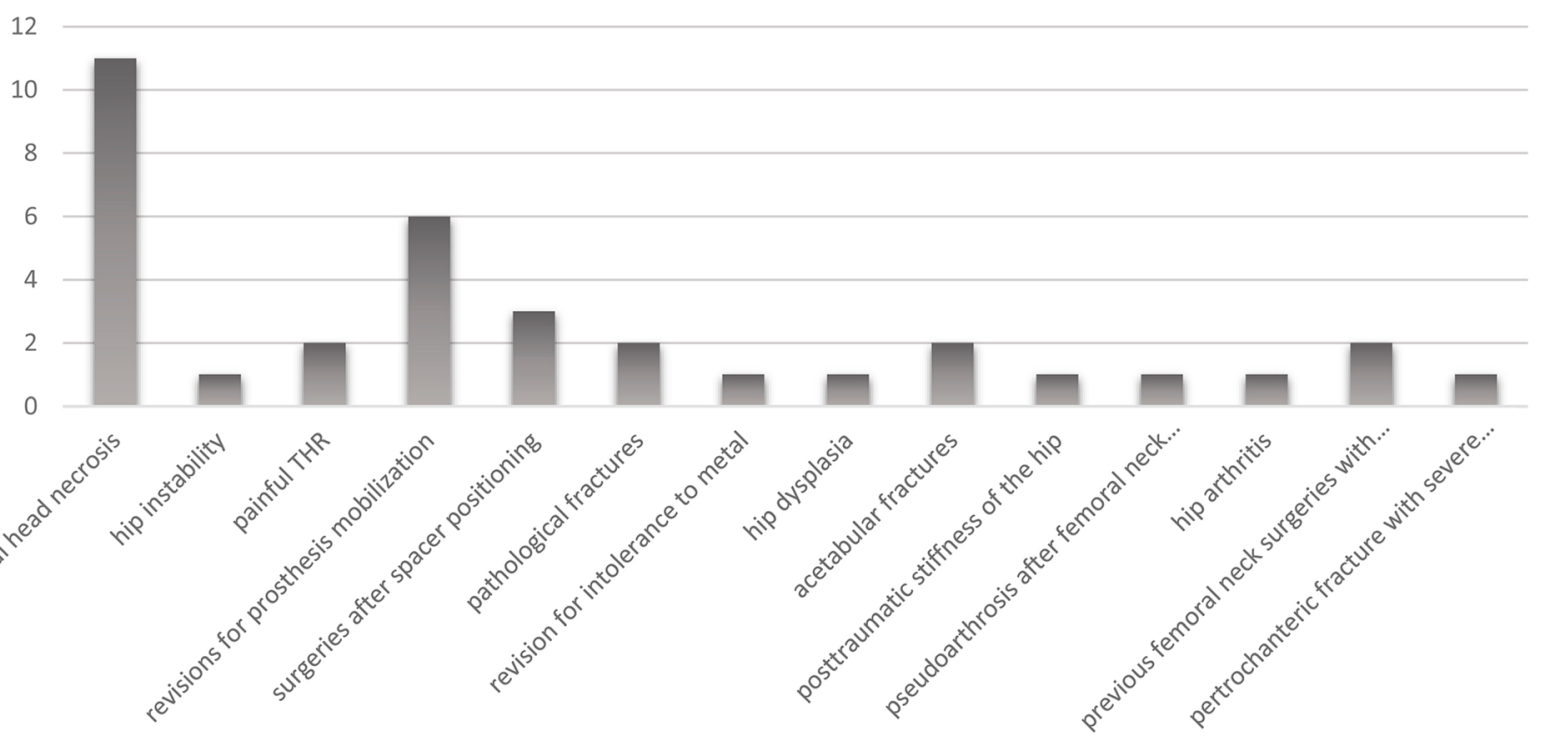

Fig. 1 Distribution of the diagnoses of a diseased hip. a Main diagnoses. b Diagnoses included under "others" 
(Fig. 1). Forty-two patients (6.45 \%) had already developed $\mathrm{HO}$ after previous surgery of the ipsilateral and/or contralateral hip. With regard to the population which underwent ceramic-ceramic THR, 20 (8.73\%) patients had already undergone a previous surgical intervention of the ipsilateral coxofemoral joint. All operations were carried out adopting one of the following two surgical approaches to the hip:

1. Transgluteal approach (Hardinge-Bauer) in 223 (34.25\%) patients

2. Anterolateral approach (Watson-Jones) in 401 (61.60\%) patients

For 27 (4.15\%) subjects included in the study, there were no data available in our archives concerning the surgical approach to the hip.

Patients underwent hip surgery with three kinds of implants:

1. Ceramic-ceramic THR: 229 (35.18\%) patients

2. TriboFit system with polycarbonate urethaneceramic coupling: $112(17.20 \%)$ patients

3. Endoprosthesis: 310 (47.62\%) patients

Periarticular HO formed in $59.9 \%(390 / 651)$ of the patients (Fig. 2). Among these, 135 (34.6\%) had mild HO (grade 1, Brooker classification); 107 (27.4\%) had moderate HO (grade 2, Brooker classification); 120 (30.8 \%) had severe $\mathrm{HO}$ (grade 3, Brooker classification); and 28 (7.2\%) showed very severe $\mathrm{HO}$ (grade 4, Brooker classification). The pictures taken at the operating table show grade 4 HOs that developed in a patient of our cohort who was moved to the emergency room because of her critical condition after the operation (Fig. 3).

Preoperative and operative independent variables were considered for those patients who developed periarticular $\mathrm{HO}$ after surgery as shown in Table 1 . The mean patient age at the time of the surgery among those who showed $\mathrm{HO}$ formation was 77.6 years, compared to the mean age of 80.2 years among those who did not develop HO. Among male patients, 136 subjects formed HO, whereas among female they were 254. Periarticular ossification was found in 289 subjects with preoperative diagnosis of femoral neck fracture; 72 subjects with diagnosis of coxarthrosis and 29 subjects with other diagnoses. Among the population that had shown $\mathrm{HO}$ due to previous hip surgery, 32 patients developed HOs compared to 358 among those who had previously not had HO. Considering only the patients for whom ceramic-ceramic THR was used, $\mathrm{HO}$ developed in 15 patients who had undergone previous ipsilateral hip surgery and in 141 patients who had not. Among patients for whom the surgical approach by Hardinge-Bauer was chosen, there were 146 subjects with $\mathrm{HO}$, and among patients for whom the surgical approach by Watson-Jones was preferred, HO developed in 223 cases. Radiographic signs of $\mathrm{HO}$ were found with the following frequencies for each kind of implant: 156 among ceramic-ceramic THR, 75 among Prosthesis with TriboFit technology, 159 among endoprosthesis.

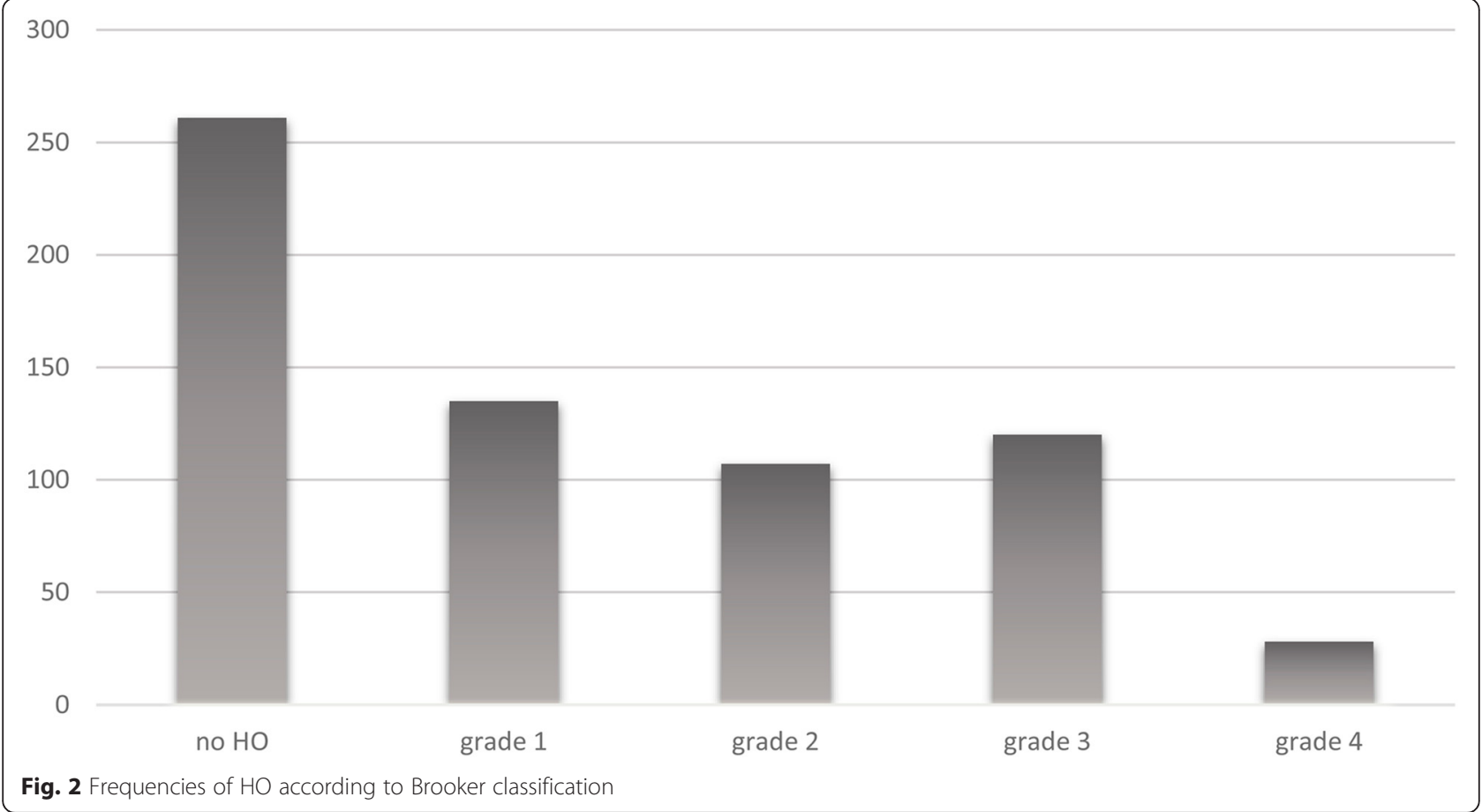




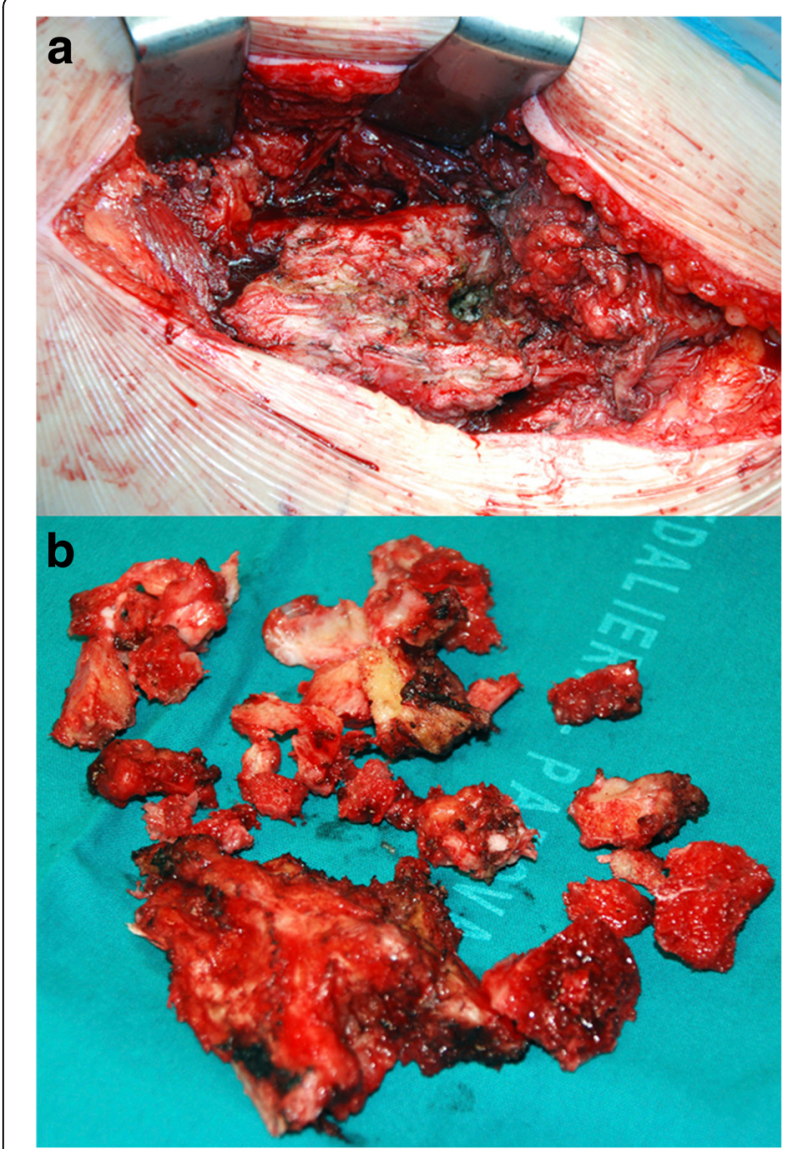

Fig. 3 Case of severe heterotopic ossifications. HOs developed in a patient who had been moved to the emergency room after ceramic-ceramic THR because of her critical condition. The patient remained motionless for 1 month after hip replacement, and 1 year later, heterotopic ossifications were removed $(\mathbf{a}, \mathbf{b})$

Multivariate analysis of those risk factors that reached statistical significance with the chi-square test was performed. Age $(p=0.7483)$, sex $(p=0.3528)$, diagnosis of diseased hip $(p=0.1658)$ and surgical approach $(p=0.0577)$ did not show to increase HO individually. Statistical significance was reached by the presence of $\mathrm{HO}$ after previous hip surgery $(p=0.0324)$ and the kind of implant $(p=0.0004)$. An OR $=2.322$ was estimated for those patients with previous ossification. Patients who were treated with TriboFit technology and ceramicceramic THR showed, respectively, an $\mathrm{OR}=1.976$ and an $\mathrm{OR}=1.911$ (Table 2). Within the population that showed periarticular $\mathrm{HO}$, each risk factor was assessed for correlation with grading of ossification by Brooker classification. The frequencies obtained are shown in Table 3.

\section{Discussion}

Development of periarticular $\mathrm{HO}$ can complicate the postoperative course of healing in those patients who undergo hip replacement surgery. Principal signs and symptoms are local pain and decreased joint mobility, and later, reduced range of motion and ankylosis of the coxofemoral joint may occur. Fortunately, 80 \% or more cases of $\mathrm{HO}$ run an asymptomatic course. Nevertheless, most studies [1] agree that the radiographic incidence of $\mathrm{HO}$ is approximately $53 \%$ of patients undergoing hip replacement without any prophylactic therapy.

This study reports retrospective data from the radiographic analysis of a cohort of 651 patients who underwent hip replacement surgery with the aim of evaluating the incidence of $\mathrm{HO}$ on the basis of different risk factors in the absence of prophylaxis. Discussing our results together with those reported in literature, another purpose is to suggest possible features that make the patients suitable for preventive measures against $\mathrm{HO}$ following hip replacement surgery. Of examined patients, 59.9 \% (390/651) developed periarticular $\mathrm{HO}$ following hip replacement surgery. This result, apparently negative, does not deviate from the mean value reported in similar studies [1] where patients did not undergo any prophylaxis. Instead, an aspect that seems relevant is the high percentage of cases that showed severe or very severe ossification by Brooker classification (38\%), with a variable incidence reported in the literature [7] between 3 and $55 \%$ (Fig. 4). This result could be justified by the choice of surgical approaches that could have contributed negatively. In this study, only two surgical approaches were examined, anterolateral and lateral, both believed liable to cause a higher incidence of $\mathrm{HO}$ by several authors $[9,10]$.

A wide meta-analysis published in the Cochrane Library [14] has proven a reduction of 54-64\% in HO incidence with an adequate prophylactic therapy. If applied to this study, these percentages would decrease our incidence of $\mathrm{HO}$ to about $30 \%$, and it would be a value comparable with those reported by authors [14] who adopted a prophylactic therapy. Thus, our data confirm that the absence of a perioperative prophylaxis seems to be one of the principal causes of a high incidence of HO. The different risk factors implicated in their development are discussed below.

\section{Age}

The mean age of patients who developed $\mathrm{HO}$ was 77.6 years, and it was significantly lower (two-sided $p=0.0018$ ) when compared to that of patients who did not develop HO (80.2 years). This result refutes some studies [21] which consider older age as a risk factor for $\mathrm{HO}$.

\section{Sex}

Among males, 64.4\% underwent periarticular soft tissue $\mathrm{HO}$ versus $57.7 \%$ of females. Even if this trend is in agreement with the literature $[1,5,22]$, variance in our study was not statistically relevant $(p=0.1011)$. 
Table 1 Distribution of development of heterotopic ossifications ( $\mathrm{HO})$ among patients by rank

\begin{tabular}{|c|c|c|c|c|}
\hline Character & Rank & Presence of $\mathrm{HO}(\%)$ & Absence of $\mathrm{HO}(\%)$ & $p$ values \\
\hline Age & & Mean age $=77.6$ years & Mean age $=80.2$ years & 0.0018 \\
\hline \multirow[t]{2}{*}{ Sex } & Male & 64.4 & 35.6 & \multirow[t]{2}{*}{0.1011} \\
\hline & Female & 57.7 & 42.3 & \\
\hline \multirow[t]{3}{*}{ Diagnosis of diseased hip } & Coxarthrosis & 72.7 & 27.3 & \multirow[t]{3}{*}{0.0001} \\
\hline & Femoral neck fracture & 55.9 & 44.1 & \\
\hline & Others & 82.9 & 17.1 & \\
\hline \multirow[t]{2}{*}{ Previous $\mathrm{HO}$} & Presence & 76.2 & 23.8 & \multirow[t]{2}{*}{0.0260} \\
\hline & Absence & 58.8 & 41.2 & \\
\hline \multirow[t]{2}{*}{ Surgical approach to the hip } & Watson-Jones & 55.6 & 44.4 & \multirow[t]{2}{*}{0.0163} \\
\hline & Hardinge-Bauer & 65.5 & 34.5 & \\
\hline \multirow[t]{3}{*}{ Kind of implant } & Ceramic-ceramic THR & 68.1 & 31.9 & \multirow[t]{3}{*}{0.0001} \\
\hline & Partial prosthesis & 51.3 & 48.7 & \\
\hline & TriboFit system & 67.0 & 33.0 & \\
\hline \multirow{2}{*}{$\begin{array}{l}\text { Previous surgery of the ipsilateral hip } \\
\text { (only among ceramic-ceramic THR) }\end{array}$} & Presence & 75.0 & 25.0 & \multirow[t]{2}{*}{0.4896} \\
\hline & Absence & 67.5 & 32.5 & \\
\hline
\end{tabular}

\section{Diagnosis of diseased hip}

Statistical significance was reached comparing the percentage of patients who developed $\mathrm{HO}$ on the basis of the diagnosis of diseased hip $(p=0.0001)$. Femoral neck fracture predisposes less than coxarthrosis to the development of ectopic bone, probably because operating time is reduced and so are muscular traumatic damage and bleeding. However, the role of some inflammatory pathologies (above all, hypertrophic osteoarthritis) as predictive factors for $\mathrm{HO}$ has been well documented in the literature [7]. In fact, inflammation, which is greater in osteoarthritis than in acute events like femoral neck fracture, could justify the difference in the incidences that we found.

\section{Previous HO}

In agreement with the literature [6], patients who developed $\mathrm{HO}$ after previous hip surgery showed a higher statistically significant frequency $(p=0.0260)$ of HO than patients with a history of hip surgery but no HO. This

Table $\mathbf{2}$ Odds ratio estimates for those variables that showed to increase the development of periarticular $\mathrm{HO}$ individually during multivariate analysis

\begin{tabular}{lll}
\hline Effect & Point estimate & $\begin{array}{l}95 \% \text { Wald } \\
\text { confidence limits }\end{array}$ \\
\hline TriboFit vs endoprosthesis & 1.976 & $1.251-3.121$ \\
Ceramic-ceramic-coupled & 1.911 & $1.326-2.752$ \\
THR vs endoprosthesis & & \\
$\begin{array}{l}\text { Presence of previous HO } \\
\text { vs absence of previous HO }\end{array}$ & 2.322 & $1.073-5.025$ \\
\hline HO heterotopic ossification & &
\end{tabular}

$\mathrm{HO}$ heterotopic ossification aspect can be explained with a subjective predisposition to develop $\mathrm{HO}$.

\section{Previous surgery of the ipsilateral hip}

In contrast to the trend found in the literature [6], among subjects with ceramic-ceramic THR, a statistically significant difference was not detected between patients who had undergone prior ipsilateral hip surgery and those who had not $(p=0.4896)$.

\section{Surgical approach to the hip}

The comparison between the two surgical approaches to the hip showed a statistically significant variance on the formation of periarticular HO $(p=0.0163)$. The HardingeBauer surgical approach is a more predisposing factor for $\mathrm{HO}$ development than the Watson-Jones surgical approach. However, several studies $[9,10]$ demonstrate that both surgical approaches predispose the development of HO more than a posterior approach. A recent study [23] found that an anterior minimally invasive approach has some advantages: lower incidence of muscle damage and haematoma, shorter operative and exposure time, less bleeding and immediate rehabilitation. All of these are preventive factors for HO. In particular, prolonged operative time has been associated to an increased development of ectopic bone, such as intraoperative blood loss, even if the latter has not been confirmed by some authors [6, 24]. A minimally invasive anterior approach, where possible, is to be preferred as opposed to lateral or anterolateral approaches, to reduce the formation of HO. The possibility of early rehabilitation given by a minimally invasive technique also seems to be useful in preventing $\mathrm{HO}$ [25]. Some pictures taken at the operating table are shown as 
Table 3 Distribution of development of heterotopic ossifications $(\mathrm{HO})$ among patients by the grade of $\mathrm{HO}$

\begin{tabular}{|c|c|c|c|c|c|c|}
\hline \multirow[t]{2}{*}{ Character } & \multirow[t]{2}{*}{ Rank } & \multicolumn{4}{|c|}{ HO grade by Brooker classification (\%) } & \multirow[t]{2}{*}{$p$ values } \\
\hline & & 1 & 2 & 3 & 4 & \\
\hline \multirow[t]{2}{*}{ Sex } & Male & 26.5 & 28.7 & 34.5 & 10.3 & 0.0478 \\
\hline & Female & 39.0 & 26.8 & 28.7 & 5.5 & \\
\hline \multirow[t]{3}{*}{ Diagnosis of diseased hip } & Coxarthrosis & 40.3 & 20.8 & 29.2 & 9.7 & 0.3278 \\
\hline & Femoral neck fracture & 33.6 & 28.4 & 32.1 & 5.9 & \\
\hline & Others & 31.0 & 34.5 & 20.7 & 13.8 & \\
\hline \multirow[t]{2}{*}{ Previous $\mathrm{HO}$} & Presence & 40.6 & 38.4 & 15.6 & 9.4 & 0.2830 \\
\hline & Absence & 34.1 & 26.8 & 32.1 & 7.0 & \\
\hline \multirow[t]{2}{*}{ Surgical approach to the hip } & Watson-Jones & 38.1 & 28.7 & 26.9 & 6.3 & 0.1738 \\
\hline & Hardinge-Bauer & 30.8 & 24.7 & 37.0 & 7.5 & \\
\hline \multirow[t]{3}{*}{ Kind of implant } & Ceramic-ceramic THR & 37.2 & 25.6 & 26.9 & 10.3 & 0.0093 \\
\hline & Partial prosthesis & 35.2 & 33.3 & 27.1 & 4.4 & \\
\hline & TriboFit system & 28.0 & 18.7 & 46.7 & 6.6 & \\
\hline
\end{tabular}

an example of how important early rehabilitation is (Fig. 3). This patient of our cohort was moved to the emergency room because of her critical condition before (ASA 3) and after the operation and remained motionless for about 1 month in the resuscitation unit. The grade $4 \mathrm{HOs}$ that developed were surgically removed after 1 year.

\section{Kind of implant}

The three different kinds of implants that were objects of study also seemed to have a statistically significant difference in developing ectopic periarticular bone $(p=0.0001)$. While operations carried out with TriboFit and ceramicceramic-coupled THR were complicated by $\mathrm{HO}$ in 67 and $68.1 \%$ of cases, respectively, endoprosthesis showed a lower incidence $(51.3 \%)$. We did not find comparable data in the literature. Probably, some reasons for this difference are the shorter operative and exposure time and the lesser invasivity (most of all, the loss of the acetabular reaming) that characterizes endoprosthesis when compared to TriboFit and ceramic-ceramic-coupled THR. The muscle damage, which is more probable when arthroprosthesis is performed, could also play a role in the development of HO. Thus, hip replacement with endoprosthesis reduces the incidence of ectopic ossification; this aspect should be considered when the kind of implant is chosen in borderline cases.

\section{Multivariate analysis}

During the multivariate analysis of those risk factors that reached statistical significance with the chi-square test, variables that showed to individually increase $\mathrm{HO}$ incidence were the presence of $\mathrm{HO}$ after previous hip surgery $(p=0.0324)$ and the kind of implant $(p=0.0004)$. In particular, an $\mathrm{OR}=2.322$ was estimated for those patients with previous ossification in comparison to those patients who had undergone prior hip surgery without $\mathrm{HO}$. Patients who were treated with TriboFit technology and ceramic-ceramic THR showed, respectively, an $\mathrm{OR}=1.976$ and an $\mathrm{OR}=1.911$ compared to patients treated with endoprosthesis.

Within the population of subjects that showed periarticular $\mathrm{HO}$, each detected variable was assessed for correlation with the severity of ossification according to Brooker classification. Factors that did not indicate a significant influence on grading of ossification were diagnosis of diseased hip $(p=0.3278)$, surgical approach to the hip $(p=0.1738)$ and HO due to previous hip surgery $(p=0.2830)$.

\section{Development of HO following Brooker classification}

On the other hand, association between the severity of $\mathrm{HO}$ and the following factors turned out to be statistically significant:

1. Kind of implant $(p=0.0093)$. In particular, with patients who underwent ceramic-ceramic-coupled THR and TriboFit, respectively, 37.2 and $53.3 \%$ of cases developed ossification of grades 3 and 4, versus $31.4 \%$ of patients whose implant was an endoprosthesis.

2. Gender $(p=0.0478)$. Male patients showed a percentage of $44.8 \%$ of severe or very severe ossification, versus $34.2 \%$ of female patients, in agreement with literature data $[1,5,22]$.

Some data presented in this study may encourage improvement of the prophylactic drugs against formation of periarticular $\mathrm{HO}$ and early rehabilitation. However, our study shows some weaknesses, which should be pointed out. First of all, we did not consider the clinical 


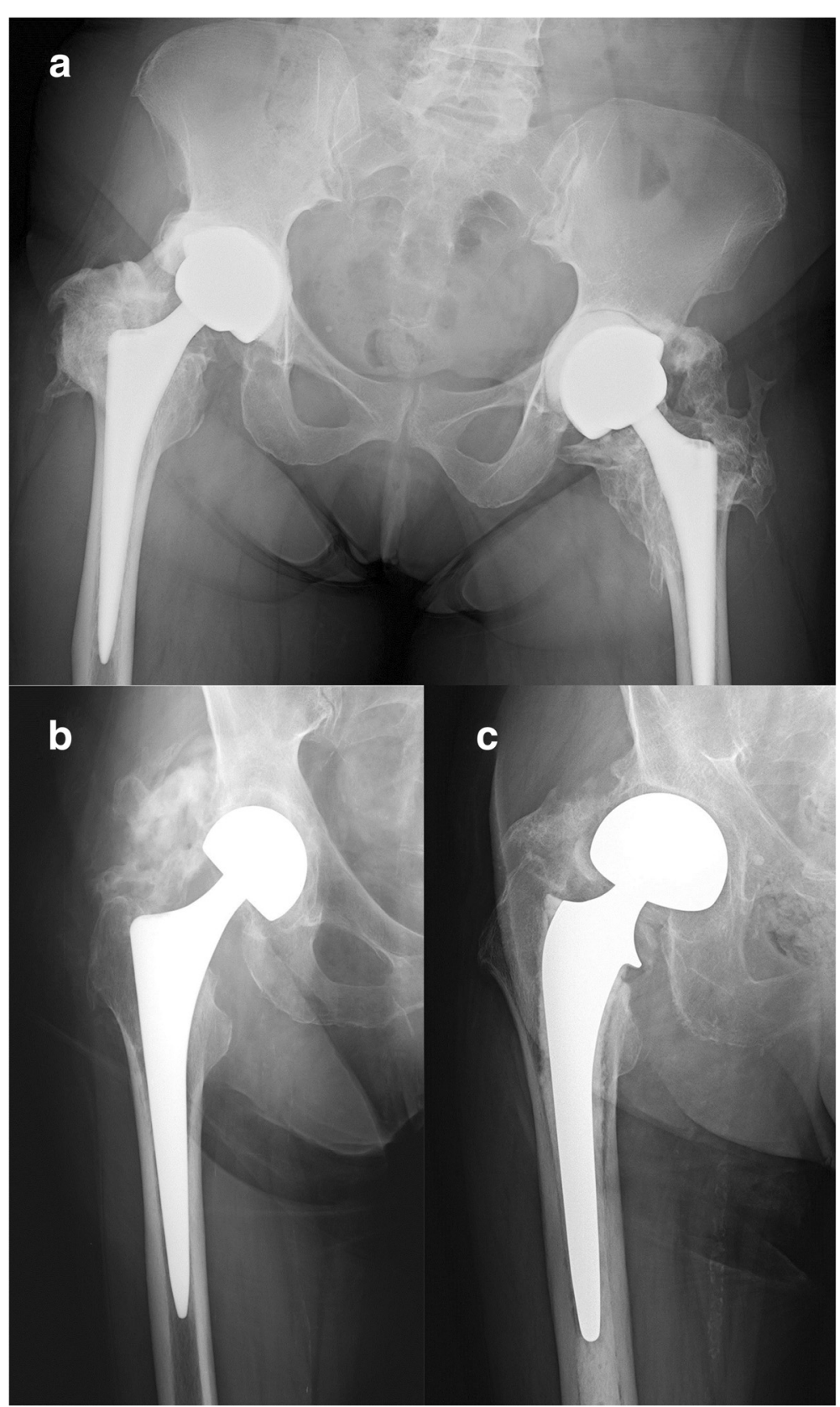

Fig. 4 Examples of radiographic high-graded heterotopic ossification for each kind of implant within our cohort. a Ceramic-ceramic-coupled total hip replacement. b TriboFit'. c Endoprosthesis

counterpart of the HOs found. Usually, radiographic $\mathrm{HO}$ is not related to clinical course and most HOs occur asymptomatically; they may, however, involve clinical impairment, such as decreased hip range of motion and function and pain [26-28]. Hence, we strongly believe that further research is necessary to establish a relationship between the radiographic grade of $\mathrm{HO}$ and its clinical aspect. Another apparent point of weakness is that we considered the presence in our computerized database of a minimum follow-up control at 6 months from hip surgery as an inclusion criterion (only nine patients with a minimum follow-up of 6 months, seven patients with an 8-month follow-up and six with a 10-month follow-up). Considering this period reasonable to observe or predict the development of $\mathrm{HO}$, we could have slightly underestimated the number of patients which developed $\mathrm{HO}$ and, in particular, the number of severe and very severe HOs (grades 3 and 4 by Brooker classification). However, $\mathrm{HO}$ is usually evident from radiographs by 6 weeks after surgery. Hence, the ossification 
matures throughout the first 6 months and then generally does not develop further thereafter [13, 26, 27].

Finally, the fact that our institute is a trauma clinic could have introduced some difficulties of interpretation. In particular, $80 \%$ of the population studied suffered from femoral neck fracture and only $15 \%$ from coxarthrosis. A bias towards endoprosthesis in fracture and THR in hip osteoarthrosis is plausible. However, we used logistic regression as our statistical modelling method to control confounding variables as much as possible. According to our knowledge, in the literature, there are no comparable data about the relationship between $\mathrm{HO}$ and the kind of implants considered in this study. This variable was shown to affect the development of $\mathrm{HO}$ in our research, and further studies are needed to confirm our results. Moreover, the presence of a higher incidence of $\mathrm{HO}$ in AfricanAmerican patients following acetabular fracture surgery [12] and in the Japanese population because of multiple injuries, nerve injuries and ossificans diseases [2-4] should be investigated further. In addition, our data should be compared with other ethnic groups as our study was conducted only with a cohort of Caucasian subjects.

\section{Conclusions}

The development of HO following hip replacement surgery is affected by endogenous and exogenous factors. Our radiographic study confirms, in agreement with the literature, some risk factors, such as previous $\mathrm{HO}$ of soft tissue around the hip, kind of implant, surgical approach to the hip, diagnosis of coxarthrosis versus femoral neck fracture and male gender. On the other hand, there are factors in contrast with some of the authors' outcomes, such as older age. In particular, HardingeBauer and Watson-Jones surgical approaches, characterized by a wide exposure of the coxofemoral joint, and ceramic-ceramic THR and TriboFit significantly favour the formation of HO. Thus, we think that orthopaedic surgeons should prefer alternative surgical approaches and minimally invasive implants. Furthermore, our results and literature data suggest that a prophylactic treatment could be a choice to drastically decrease the incidence of $\mathrm{HO}$ after hip replacement surgery. We believe it is necessary to carry out a controlled and randomized study as a valid aid for the choice of the most appropriate therapeutic option according to different categories of patients.

\section{Abbreviations}

HO: heterotopic ossification; NSAIDs: nonsteroidal anti-inflammatory drugs; THR: total hip replacement.

\section{Competing interests}

The authors declare that they have no competing interests.

\section{Authors' contributions}

$\mathrm{CB}$ and $\mathrm{AF}$ helped in the study concept and design and drafting the paper. DP helped in data collection and statistical analysis. AB helped in the analysis and interpretation of data. $\mathrm{Cl}$ helped in the study concept and final approval of the version to be published. The manuscript has been read and approved by all the listed authors, who declare that this article represents honest work.

\section{Author details}

'Orthopaedic and Traumatology Clinic, Department of Surgery, Oncology and Gastroenterology DiSCOG, University of Padua, via Giustiniani 2, 35128 Padova, Italy. ${ }^{2}$ Department of Orthopaedic Rehabilitation, University of Padua, via Giustiniani 2, 35128 Padova, Italy.

Received: 4 June 2015 Accepted: 8 November 2015

Published online: 14 November 2015

\section{References}

1. Shehab D, Elgazzar AH, Collier BD. Heterotopic ossification. J Nucl Med. 2002:43:346-53.

2. Bossche LV, Vanderstraeten G. Heterotopic ossification: a review. J Rehabil Med. 2005;37:129-36.

3. Ranganathan K, Loder S, Agarwal S, Wong WW, Forsberg J, Davis TA, et al. Heterotopic ossification: basic-science principles and clinical correlates. J Bone Joint Surg Am Jul. 2015:97(13):1101-11.

4. Bruno-Petrina A. Posttraumatic heterotopic ossification. EMed J. 2002;29(3):11. Available from: http://www.emedicine.com/pmr/topic112.htm. Accessed on 27 Apr 2015.

5. Cohn RM, Schwarzkopf R, Jaffe F. Heterotopic ossification after total hip arthroplasty. Am J Orthop. 2011;40(11):E232-5.

6. Toom A, Haviko T, Rips L. Heterotopic ossification after total hip arthroplasty. Int Orthop. 2001;24(6):323-6.

7. Goel A, Sharp DJ. Heterotopic bone formation after hip replacement. The influence of the type of osteoarthritis. J Bone Joint Surg Br. 1991;73(2):255-7.

8. Tomasz S, Bogdan K, Wojciech W, Leszek M. Heterotopic ossification in patients after total hip replacement. Ortop Traumatol Rehabil. 2007;9(3):264-72.

9. Morrey BF, Adams RA, Cabanela ME. Comparison of heterotopic bone after anterolateral, transtrochanteric, and posterior approaches for total hip arthroplasty. Clin Orthop. 1984;188:160-7.

10. Eggli S, Woo A. Risk factors for heterotopic ossification in total hip arthroplasty. Arch Orthop Trauma Surg. 2001;121(9):531-5.

11. Bal BS, Lowe JA, E Gietler A, Aleto TJ. Heterotopic ossification after 2 incision total hip arthroplasty. J Arthroplasty. 2010;25(4):538-40.

12. Slone HS, Walton ZJ, Daly CA, Chapin RW, Barfield WR, Leddy LR, et al. The impact of race on the development of severe heterotopic ossification following acetabular fracture surgery. Injury. 2015;46(6):1069-73.

13. Brooker AF, Bowerman JW, Robinson RA, Riley Jr LH. Ectopic ossification following total hip replacement. Incidence and a method of classification. J Bone Joint Surg Am. 1973;55(8):1629-32.

14. Fransen $M$, Neal B. Non-steroidal anti-inflammatory drugs for preventing heterotopic bone formation after hip arthroplasty. Cochrane Database Syst Rev. 2013;3:CD001160.

15. Barbato M, D'Angelo E, Di Loreto G, Menna A, Di Francesco A, Salini V, et al. Adherence to routine use of pharmacological prophylaxis of heterotopic ossification after total hip arthroplasty: results from an Italian multicenter, prospective, observational survey. J Orthopaed Traumatol. 2012;13:63-7.

16. Xue D, Zheng Q, Li H, Qian S, Zhang B, Pan Z. Selective COX-2 inhibitor versus nonselective COX-1 and COX-2 inhibitor in the prevention of heterotopic ossification after total hip arthroplasty: a meta-analysis of randomised trials. Int Orthop (SICOT). 2011;35:3-8.

17. Sakurai T, Sawada Y, Yoshimoto M, Kawai M, Miyakoshi J. Radiation-induced reduction of osteoblast differentiation in C2C12 cells. J Radiat Res. 2007; 48(6):515-21.

18. Leonardi F, Gioga G, Coeli M, Ruffo P, Agus G, Pizzoli A, et al. Preoperative, single-fraction irradiation for prophylaxis of heterotopic ossification after total hip arthroplasty. Int Orthop (SICOT). 2001;25:371-4.

19. Le Duff MJ, Takamura KB, Amstutz HC. Incidence of heterotopic ossification and effects of various prophylactic methods after hip resurfacing. Bull NYU Hosp Jt Dis. 2011;69 Suppl 1:S36-4.

20. Pakos EE, Pitouli EJ, Tsekeris PG, Papathanasopoulou V, Stafilas K, Xenakis TH. Prevention of heterotopic ossification in high-risk patients with total hip 
arthroplasty: the experience of a combined therapeutic protocol. Int Orthop (SICOT). 2006:30:79-83.

21. Ahrengart $L$, Lindgren U. Heterotopic bone after hip arthroplasty. Defining the patient at risk. Clin Orthop. 1993;293:153-9.

22. McCarthy EF, Sundaram M. Heterotopic ossification: a review. Skeletal Radiol. 2005;34:609-19.

23. Unger AC, Schulz AP, Peach A, Jurgens C, Renken FG. Modified direct anterior approach in minimally invasive hip hemiarthroplasty in a geriatric population: a feasibility study and description of the technique. Arch Orthop Trauma Surg. 2013;133(11):1509-16.

24. Fransen M, Neal B, Cameron ID. Determinants of heterotopic ossification after total hip replacement surgery. Hip Int. 2009;19(1):41-6.

25. Kocic M, Lazovic Z, Mitkovic M, Milenkovic S, Cinic T. Methods of the physical medicine therapy in prevention of heterotopic ossification after total hip arthroplasty. Vojnosanit Pregl. 2006;63:807.

26. Tippets DM, Zaryanov AV, Burke W, Patel PD, Suarez JC, Ely EE, et al. Incidence of heterotopic ossification in direct anterior total hip arthroplasty: a retrospective radiographic review. J Arthroplasty. 2014;29:1835-8.

27. Ritter MA, Vaughan RB. Ectopic ossification after total hip arthroplasty. Predisposing factors, frequency, and effect on results. J Bone Joint Surg Am. 1977:59(3):345-51

28. Kocic M, Lazovic M, Mitkovic M, Djokic B. Clinical significance of heterotopic ossification after total hip arthroplasty. Orthopedics. 2010;33(1):16.

\section{Submit your next manuscript to BioMed Central and take full advantage of:}

- Convenient online submission

- Thorough peer review

- No space constraints or color figure charges

- Immediate publication on acceptance

- Inclusion in PubMed, CAS, Scopus and Google Scholar

- Research which is freely available for redistribution 